\title{
Performance of Automated Attenuation Measurements at Identifying Large Vessel Occlusion Stroke on CT Angiography
}

\author{
Paul Reidler ${ }^{1}$ D $\cdot$ Lena Stueckelschweiger ${ }^{1}$ Daniel Puhr-Westerheide ${ }^{1} \cdot$ Katharina Feil $^{2,3} \cdot$ Lars Kellert $^{2}$. \\ Konstantinos Dimitriadis ${ }^{2,4}$. Steffen Tiedt ${ }^{4}$ - Moriz Herzberg ${ }^{5}$. Jan Rémi ${ }^{2}$. Thomas Liebig ${ }^{5}$. \\ Matthias P. Fabritius ${ }^{1}$. Wolfgang G. Kunz ${ }^{1}$
}

Received: 7 July 2020 / Accepted: 17 August 2020 / Published online: 16 September 2020

(C) The Author(s) 2020

\begin{abstract}
Purpose Computed tomography angiography (CTA) is routinely used to detect large-vessel occlusion (LVO) in patients with suspected acute ischemic stroke; however, visual analysis is time consuming and prone to error. To evaluate solutions to support imaging triage, we tested performance of automated analysis of CTA source images (CTASI) at identifying patients with LVO.

Methods Stroke patients with LVO were selected from a prospectively acquired cohort. A control group was selected from consecutive patients with clinically suspected stroke without signs of ischemia on CT perfusion (CTP) or infarct on follow-up. Software-based automated segmentation and Hounsfield unit (HU) measurements were performed on CTASI for all regions of the Alberta Stroke Program Early CT score (ASPECTS). We derived different parameters from raw measurements and analyzed their performance to identify patients with LVO using receiver operating characteristic curve analysis.

Results The retrospective analysis included 145 patients, 79 patients with LVO stroke and 66 patients without stroke. The parameters hemispheric asymmetry ratio (AR), ratio between highest and lowest regional AR and M2-territory AR produced area under the curve (AUC) values from 0.95-0.97 (all $p<0.001$ ) for detecting presence of LVO in the total population. Resulting sensitivity (sens)/specificity (spec) defined by the Youden index were 0.87/0.97-0.99. Maximum sens/spec defined by the specificity threshold $\geq 0.70$ were $0.91-0.96 / 0.77-0.83$. Performance in a small number of patients with isolated M2 occlusion was lower (AUC: 0.72-0.85).

Conclusion Automated attenuation measurements on CTASI identify proximal LVO stroke patients with high sensitivity and specificity. This technique can aid in accurate and timely patient selection for thrombectomy, especially in primary stroke centers without CTP capacity.
\end{abstract}

Keywords Stroke $\cdot$ Perfusion $\cdot$ Stroke triage $\cdot$ Automated analysis $\cdot$ Thrombectomy

M.P. Fabritius and W.G. Kunz contributed equally.

Availability of Data and Material The data that supports our findings are made available by the corresponding author upon reasonable request.

Electronic supplementary material The online version of this article (https://doi.org/10.1007/s00062-020-00956-5) contains supplementary material, which is available to authorized users.

Paul Reidler

paul.reidler@med.uni-muenchen.de
1 Department of Radiology, University Hospital, LMU Munich, Marchioninistr. 15, 81377 Munich, Germany

2 Department of Neurology, University Hospital, LMU Munich, Marchioninistr. 15, 81377 Munich, Germany

3 German Center for Vertigo and Balance Disorders, LMU Munich, Marchioninistr. 15, 81377 Munich, Germany

4 Institute for Stroke and Dementia Research, LMU Munich, Feodor-Lynen-Str. 17, 81377 Munich, Germany

5 Department of Neuroradiology, University Hospital, LMU Munich, Marchioninistr. 15, 81377 Munich, Germany 


\section{Introduction}

Detection of large vessel occlusion (LVO) in patients with suspected ischemic stroke is the most critical diagnostic challenge in acute stroke imaging. LVO stroke contributes to around $60 \%$ of stroke disability and $90 \%$ of stroke mortality, although only representing $24-38 \%$ of cases $[1,2]$. Since the positive endovascular thrombectomy (EVT) trials of 2015 [3] and the recent studies on EVT beyond 6h [4, 5], LVO patients require this highly effective treatment to ensure the best possible clinical outcome.

In most stroke treating facilities, single-phase computed tomography angiography (CTA) is the primary imaging modality to detect LVO and prompt further treatment or transfer to comprehensive stroke centers [6]. The latter is a common scenario in primary stroke centers (PSC) with often limited imaging capacities and imaging interpretation by less experienced readers compared to high-volume centers $[6,7]$.

Considering the literature, visual detection rate of LVO on CTA varies considerably with reported rates of missed LVO around 20\% [8,9]. While multiphase CTA and CT perfusion (CTP) provide added value for LVO detection, they are not universally available, especially in smaller stroke treating facilities $[6,9,10]$. Therefore, improving diagnostic confidence at single-phase CTA could ensure correct and timely stroke triage, for example to decide patient transfer.

In spite of encouraging results on CTA hypoattenuation to detect ischemia, this imaging biomarker is currently underused and not recommended in the latest guidelines [11]; however, hypoattenuation on CTA has frequently been shown to present substantial overlap with highly sensitive maps derived from CTP [12]. Combined with automated assessment, hypoattenuation on CTA therefore has the potential to aid as reader-independent, sensitive tool for ischemia detection.

To address the clinical value of automated attenuation analysis in single-phase CTA data, we evaluated its performance in detecting stroke patients with LVO of the anterior circulation and consequent ischemia in the medial cerebral artery (MCA) territory among a population of patients with suspected ischemic stroke.

\section{Material and Methods}

\section{Study Design and Population}

The retrospective study was approved by the institutional review board according to the Declaration of Helsinki of 2013 and requirement for written informed consent was waived. Patients with acute ischemic stroke due to anterior circulation large vessel occlusion were selected out of a consecutive cohort of 274 patients who were prospectively enrolled in the German Stroke Registry (clinicaltrials.gov identifier: NCT03356392). All patients were directly admitted to our institution and treated with EVT between 2015 and 2017. In total, we selected 79 LVO patients.

We included patients with:

1. internal carotid artery, M1 or M2 segment artery occlusion,

2. complete noncontrast $\mathrm{CT}$, single-phase $\mathrm{CT}$ angiography, and CTP imaging data.

We excluded patients with:

1. prior ischemia or intracranial mass, to ensure unbiased measurement of HU values,

2. pathology of the posterior circulation,

3. non-diagnostic imaging data.

From a consecutive cohort of 664 patients between 2015 and 2016 we further selected patients who underwent full imaging assessment for suspected stroke but did not present signs of ischemia at admission or infarction at follow-up to build a stroke negative control group. Otherwise the same exclusion criteria were applied as before. This led to the inclusion of 66 patients.

All 79 LVO stroke patients were previously reported in a study on automated attenuation measurements in ASPECTS regions on noncontrast CT [13]. The previous article dealt with the classification of CTP-based criteria for late time window thrombectomy [5] on noncontrast CT data, whereas the current study uses CTA data to classify the presence of large-vessel occlusion stroke. Another study incorporating only the $79 \mathrm{LVO}$ patients analyzed the overlap of CTA attenuation measurements with acute and final stroke morphology (under review). The 66 patients of the stroke negative cohort have not been previously reported.

A detailed flow-chart of patient selection is provided in Figure I of the online supplemental material.

\section{Image Analysis}

Noncontrast CT, CTA and CTP were performed using SOMATOM Definition Force, AS+ and Flash scanners (Siemens Healthineers, Forchheim, Germany). The CTP data were processed using the manufacturer's software (syngo Neuro Perfusion CT, Siemens Healthineers) to generate perfusion maps.

For CTA intravenous administration of $50 \mathrm{~mL}$ iodinated contrast medium was followed by a saline chaser of $40 \mathrm{~mL}$, each with a flow rate of $5 \mathrm{~mL} / \mathrm{s}$. Imaging was performed in a single sweep from the aortic arch to the vertex with a bolus trigger of $100 \mathrm{HU}$ in the aortic trunk. Tube voltage was $120 \mathrm{kV}$ (SOMATOM Force, Flash) or 80 kV (SOMATOM 
AS+) and tube current modulation (CareDose) was used. Collimation was $0.6 \mathrm{~mm}$.

The ASPECTS was determined by two blinded readers as described in previous studies [13]. Manual segmentation of total ischemic volume on cerebral blood flow (CBF) maps, ischemic core volume on cerebral blood volume (CBV) maps and final infarction on follow-up CT or MRI were performed using commercial software (OsiriX v. 8.0.2, Pixmeo, Bernex, Switzerland 2017). Final infarction was determined on follow-up imaging at CT or MRI.

\section{Automated Analysis of Tissue Attenuation on CTA Source Images}

We used a software prototype (Syngo Via Frontier ASPECTS, Siemens Healthineers) to analyze attenuation values in ASPECTS regions at CTA [13]. The prototype performs segmentation of all 10 ASPECTS regions on CT data using a probabilistic atlas and calculates the mean attenuation in Hounsfield Units (HU) for each region.

To establish a parameter which does not require a priori information of stroke laterality, we calculated the asymmetry ratio (AR), which was defined as the ratio of the quotients right by left and left by right regional HU, using the larger value as denominator. As we assume that patients without ischemia present similar values across hemispheres the AR should be around 1, while having lower values in stroke patients. The AR was calculated for each of the 10 ASPECTS regions. From regional AR values we derived the CTA hemispheric AR as average AR of all 10 ASPECTS regions. To represent the maximum AR difference among all regions in a subject, we calculated the ratio of the outer limits of an individual's regional values as CTA min/max AR ratio (lowest regional AR/highest regional AR). To find values sensible for M2 MCA occlusion the CTA M2 territory asymmetry ratio was defined as average AR of the ASPECTS regions insula, M2, M3, M5 and M6, which constitute the largest portion of the vascular MCA M2 segment territory. For isolated M2 occlusions we separately analyzed the CTA ASPECTS M5 region AR, as the M5 region contains the motor cortex and information about involvement can therefore aid clinical decision making in distal occlusions. No impact of microvascular or age-related white matter changes on the presented parameters was found in linear regression analysis displayed in supplemental Table I.

\section{Statistical Analysis}

Analyses were performed in SPSS Statistics 23 (IBM, Armonk NY, USA 2016, commercial software), MedCalc version 18.10.2 (MedCalc Software, Ostend, Belgium, 2018, commercial software) and $\mathrm{R}$ version 3.6 .3 (R Founda- tion for Statistical Computing, Vienna Austria). All metric and ordinal variables are reported as median (interquartile range, IQR). Categorical variables are presented as number and percentage. Receiver operating characteristic (ROC) analyses using exact binomial confidence intervals (CI) compared the diagnostic performance of parameters and area under the curve (AUC) values were calculated. Cut-off values were determined using maximization of the Youden index. To reflect the clinical importance of a high sensitivity we further determined cut-off values with maximum sensitivity at a given specificity threshold of $\geq 0.70$. To calculate the corresponding positive and negative predictive values (PPV, NPV) we assumed a $30 \%$ rate of overall LVO patients and $4 \%$ rate of $\mathrm{M} 2$ occlusion patients at stroke centers as found in the literature $[1,14]$.

\section{Results}

\section{Patient Characteristics and CTASI Attenuation Measurements}

In this study 79 patients with LVO stroke were included ( 37 female, 42 male, median age 76 years, IQR 62-82 years). Location of the most proximal occlusion was ICA in $29.1 \%$, M1 segment in $62.0 \%$ and M2 segment in $8.9 \%$. A total of 66 patients without ischemia on admission imaging or infarct on follow-up were included as the stroke negative group. Most frequent diagnoses in the stroke negative group were transient ischemic attack with $46 \%$ and epilepsy with $24 \%$. Patients in the stroke negative group presented at a younger age (median: 76 vs. 68 years, $p=0.04$ ). Detailed patient characteristics are displayed in Table 1.

The selected attenuation parameters CTA hemispheric AR, CTA min/max AR ratio, and M2 territory AR, presented highly significant differences between LVO and control patients with all $p<0.001$. The parameters were distinctly distributed in both groups as displayed by the density plots in Supplemental Figure II.

\section{Receiver Operating Characteristic Analysis of CTASI Attenuation Measurements}

The ROC curve analysis for the identification of LVO patients resulted in an AUC of 0.95-0.97 (all $p<0.001$ ) for the respective parameters considering the total study cohort. An AUC of 0.95-0.98 (all $p<0.001$ ) was achieved for LVO detection when comparing the stroke negative cohort and patients with ICA or M1 occlusion. In a small subsample of isolated M2 occlusions $(n=7)$ versus stroke negative patients AUCs were 0.72 (IQR: 0.60-0.82) for CTA hemispheric AR, 0.81 (IQR: 0.70-0.90) for CTA $\min / \mathrm{max}$ AR ratio, 0.85 (IQR: 0.84-0.97) for CTA M2 territory AR and 
Table 1 Characteristics of the study population

\begin{tabular}{|c|c|c|c|c|}
\hline & \multicolumn{2}{|c|}{$\begin{array}{l}\text { LVO stroke patients } \\
(N=79)\end{array}$} & \multicolumn{2}{|l|}{$\begin{array}{l}\text { Stroke negative patients } \\
(N=66)\end{array}$} \\
\hline \multicolumn{5}{|l|}{ Patient data } \\
\hline Male sex & 42 & $(53.2 \%)$ & 27 & $(40.9 \%)$ \\
\hline Female sex & 37 & $(46.8 \%)$ & 39 & $(59.1 \%)$ \\
\hline Median age (years) & 76 & $(64-82)$ & 69 & $(57-78)^{*}$ \\
\hline Male study population & 73 & $(63-82)$ & 69 & $(53-82)$ \\
\hline Female study population & 79 & $(74-84)$ & 69 & $(60-77)^{*}$ \\
\hline \multicolumn{5}{|l|}{ Treatment data } \\
\hline Intravenous thrombolysis & 50 & $(63 \%)$ & 11 & $(17 \%)^{*}$ \\
\hline Endovascular thrombectomy & 79 & $(100 \%)$ & 0 & $(0 \%)^{*}$ \\
\hline- & \multicolumn{2}{|c|}{ Most proximal occlusion location } & \multicolumn{2}{|l|}{ Final diagnosis } \\
\hline \multirow[t]{6}{*}{-} & ICA & $(49.4 \%)$ & TIA & $(45.5 \%)$ \\
\hline & M1 & $(88.6 \%)$ & Epilepsy & $(24.2 \%)$ \\
\hline & M2 & $(25.3 \%)$ & Vertigo disorders & $(12.1 \%)$ \\
\hline & & & Unknown & $(10.6 \%)$ \\
\hline & & & Electrolyte derailment & $(4.6 \%)$ \\
\hline & & & Migraine & $(3.0 \%)$ \\
\hline \multicolumn{5}{|l|}{ Imaging data } \\
\hline Noncontrast CT-ASPECTS & 8 & $(8-10)$ & 10 & $(10-10)^{*}$ \\
\hline Hypoperfusion volume & 143 & $(108-196)$ & NA & \\
\hline Ischemic core volume & 17 & $(9-46)$ & NA & \\
\hline Mismatch volume & 112 & $(70-151)$ & NA & \\
\hline Final infarction volume & 19 & $(6-91)$ & NA & \\
\hline \multicolumn{5}{|c|}{ Automated CTA analysis parameters } \\
\hline CTA hemispheric AR & 0.831 & $(0.788-0.888)$ & 0.977 & $(0.958-0.990) *$ \\
\hline CTA min/max AR ratio & 0.799 & $(0.751-0.844)$ & 0.941 & $(0.919-0.956)^{*}$ \\
\hline CTA M2 territory AR & 0.830 & $(0.771-0.893)$ & 0.977 & $(0.947-0.988)^{*}$ \\
\hline
\end{tabular}

Values presented are count (percentage) for categorical and median (interquartile range) for ordinal or continuous variables. All volumes are presented in $\mathrm{mL}$

ASPECTS Alberta Stroke Program Early CT Score, ICA internal carotid artery, LVO large vessel occlusion, MCA middle cerebral artery, M1 M1 segment of the MCA, M2 M2 segment of the MCA, NIHSS National Institutes of Health Stroke Scale, AR asymmetry ratio, CTA CT angiography *Indicates statistical significance with $P$ value $<0.05$

0.92 (IQR: 0.84-0.97) for CTA ASPECTS M5 region AR. In the M2 occlusion subgroup, differences between ROC curves for LVO detection did not reach statistical significance $(p>0.05)$. Detailed results of the ROC analysis are presented in Table 2, ROC curves are provided in Fig. 1.

\section{Performance Analysis of CTASI Attenuation Measurements Derived Parameters}

The different cut points derived using Youden Index or sensitivity threshold $\geq 0.70$ including their associated sensitivity/specificity and PPV/NPV are displayed in Table 3.

For the overall study population, the Youden Index cut points favored specificity $(0.97-0.99)$ over sensitivity $(0.87-0.90)$ in our data with same values for all parameters. Using a sensitivity threshold $\geq 0.70$ measurements achieved sensitivity between $0.91-0.96$ while maintaining specificity of 0.77-0.83. Consequently, PPV for Youden Index cut points were higher (0.93-0.96 vs. $0.64-0.70)$ while producing a slightly lower NPV (0.95-0.96 vs. 0.96-0.98). Considering only patients with ICA or M1 occlusion produced similar results with even higher sensitivity up to 0.99 . In the subsample with M2 occlusions CTA Hemispheric AR, CTA Min/Max AR ratio and CTA ASPECTS M5 Region AR achieved the same sensitivity of 0.71 at the predefined specificity threshold. CTA ASPECTS M5 Region AR presented higher sensitivity of 0.86 (IQR: $0.42-1.00$ ) in this subsample. Assuming the rate of $4 \% \mathrm{M} 2$ occlusion stroke patients [15], PPV reached from 0.12-0.32 and NPV from 0.98 and 0.99 . Patient examples with true/false positive and true/false negative classification are provided in Fig. 2. 
Table 2 ROC analysis for the detection of LVO patients

\begin{tabular}{|c|c|c|c|c|c|c|}
\hline$(N=145)$ & \multicolumn{2}{|c|}{ AUC $(95 \% \mathrm{CI})$} & $P$ Value & Y-Index & Y Index CP & Spec $\geq 70 \% \mathrm{CP}$ \\
\hline \multicolumn{7}{|c|}{ Overall LVO Population $(n=79)$ vs. Controls $(n=66)$} \\
\hline CTA Hemispheric AR & 0.96 & $(0.91-0.98)$ & $<0.001$ & 0.84 & 0.926 & 0.955 \\
\hline CTA Min/Max AR Ratio & 0.97 & $(0.92-0.99)$ & $<0.001$ & 0.88 & 0.810 & 0.889 \\
\hline CTA M2 Territory AR & 0.95 & $(0.90-0.98)$ & $<0.001$ & 0.84 & 0.922 & 0.941 \\
\hline \multicolumn{7}{|c|}{ ICA and M1 Occlusion $(n=72)$ vs. Controls $(n=66)$} \\
\hline CTA Hemispheric AR & 0.98 & $(0.94-1.00)$ & $<0.001$ & 0.89 & 0.926 & 0.955 \\
\hline CTA Min/Max AR Ratio & 0.98 & $(0.94-1.00)$ & $<0.001$ & 0.92 & 0.810 & 0.955 \\
\hline CTA M2 Territory AR & 0.95 & $(0.91-0.98)$ & $<0.001$ & 0.87 & 0.922 & 0.955 \\
\hline \multicolumn{7}{|c|}{ M2 Occlusion $(n=7)$ vs. Controls $(n=66)$} \\
\hline CTA Hemispheric AR & 0.72 & $(0.60-0.82)$ & 0.14 & 0.51 & 0.935 & 0.955 \\
\hline CTA Min/Max AR Ratio & 0.81 & $(0.70-0.90)$ & 0.005 & 0.57 & 0.785 & 0.889 \\
\hline CTA M2 Territory AR & 0.85 & $(0.74-0.92)$ & $<0.001$ & 0.55 & 0.941 & 0.941 \\
\hline CTA ASPECTS M5 Region AR & 0.92 & $(0.84-0.97)$ & $<0.001$ & 0.78 & 0.919 & 0.919 \\
\hline
\end{tabular}

Cut points were determined by the Y-Index and sensitivity threshold of $\geq 0.70$

ROC indicates, receiver operating characteristics, $L V O$ large vessel occlusion, $A U C$ area under the curve, $C I$ confidence interval, $Y$-Index Youden Index, Spec specificity, $C P$ cut point, $C T A C T$ angiography, $A R$ asymmetry ratio, ICA internal carotid artery, $M 1 \mathrm{M} 1$ segment of the middle cerebral artery, M2 M2 segment of the middle cerebral artery, ASPECTS Alberta Stroke Program Early CT Score

$P$ values $<0.05$ indicate statistical significance
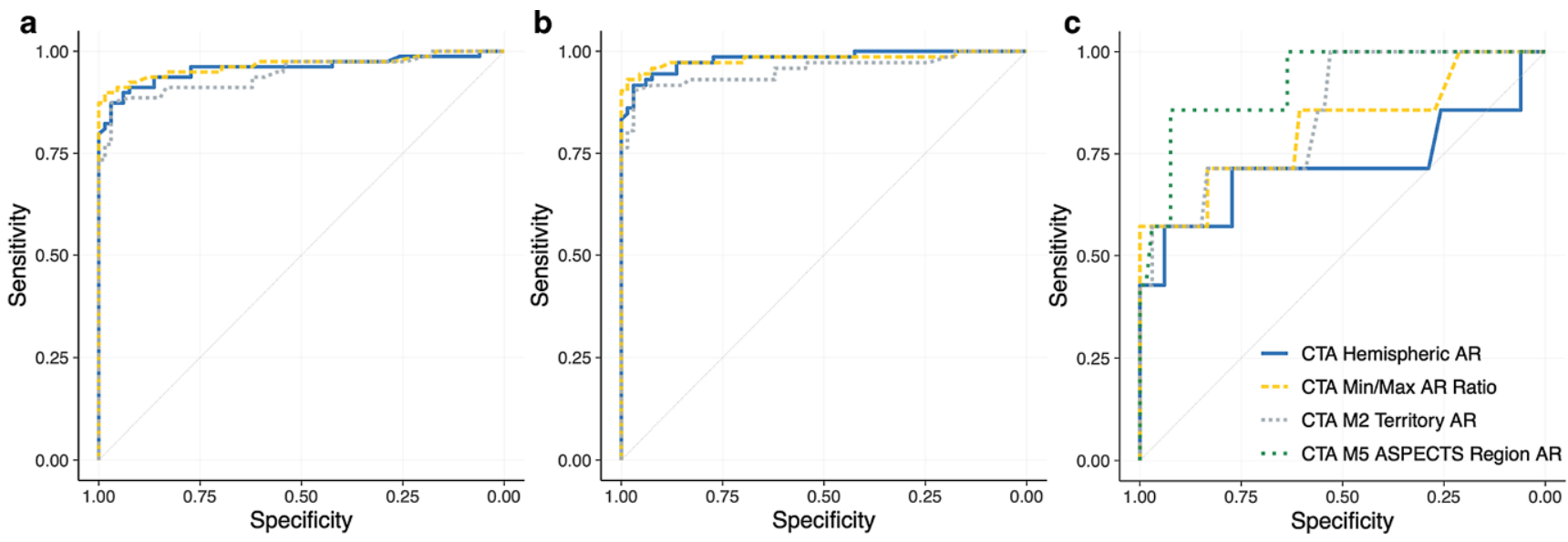

Fig. 1 Receiver operating characteristics curves for the indicated parameters to classify LVO stroke patients and stroke negative patients. a Analysis in the complete cohort (79 LVO stroke patients vs. 66 stroke negative controls), b analysis for patients with M1 and ICA occlusion (72 LVO stroke patients vs. 66 stroke negative controls), c analysis for patients with M2 occlusion (7 LVO stroke patients vs. 66 stroke negative controls) (LVO large-vessel occlusion, CTA CT angiography, M1 M1 segment of the middle cerebral artery, M2 M2 segment of the middle cerebral artery)

\section{Discussion}

Our study presents a highly sensitive automated approach to identify patients with anterior circulation LVO stroke on single-phase CTA. The performance was especially reliable in patients with ICA or M1 occlusion while presenting lower sensitivity/specificity for isolated M2 occlusions.

Although automated analysis of CTP data has reached guideline-based recommendation status [11], CTA is still mostly the domain of visual analysis. Multiple commercial software solutions for LVO detection on CTA are already available and usually implement artificial intelligence algorithms. Vendors include ischemaView (RAPID CTA, is-
chemaView inc., Menlo Park, CA, USA), Viz.ai (Viz LVO, Viz.ai, San Francisco, CA, USA), Nico.lab (Stroke Viewer, nico-lab, Amsterdam, The Netherlands) or Brainomix (eCTA, Brainomix, Oxford, UK). Reported sensitivities for LVO detection range between 0.81 and 0.97 , although data are not complete for all vendors [16-20].

While other software use direct vessel analysis for LVO detection on CTA, our regional approach of attenuation analysis determines changes in tissue perfusion comparable to highly sensitive CTP maps. In contrast to the dynamic sampling of tissue attenuation during a CTP examination, CTA provides only a single measurement timepoint, in our case, determined by the bolus dynamics in the aortic arch. 
Table 3 Performance of indicated parameters for the detection of LVO stroke patients

\begin{tabular}{|c|c|c|c|c|}
\hline Method/cut point & $\begin{array}{l}\text { Sensitivity }(95 \% \text { CI) } \\
\text { [raw \#] }\end{array}$ & $\begin{array}{l}\text { Specificity }(95 \% \text { CI) } \\
\text { [raw \#] }\end{array}$ & $\mathrm{PPV}^{*}$ & NPV* \\
\hline \multicolumn{5}{|c|}{ Overall LVO Stroke Patients $(n=79)$ vs. Controls $(n=66)$} \\
\hline \multicolumn{5}{|c|}{ CTA Hemispheric AR } \\
\hline $\begin{array}{l}\text { Y-Index } \\
\mathrm{CP}=0.926\end{array}$ & $\begin{array}{l}0.87(0.78-0.94) \\
{[69 / 79]}\end{array}$ & $\begin{array}{l}0.97(0.90-1.00) \\
{[64 / 66]}\end{array}$ & $0.93(0.76-0.98)$ & $0.95(0.91-0.97)$ \\
\hline $\begin{array}{l}\text { Specificity } \geq 0.70 \\
\mathrm{CP}=0.955\end{array}$ & $\begin{array}{l}0.96(0.89-0.99) \\
{[76 / 79]}\end{array}$ & $\begin{array}{l}0.77(0.65-0.87) \\
{[51 / 66]}\end{array}$ & $0.65(0.54-0.74)$ & $0.98(0.94-0.99)$ \\
\hline \multicolumn{5}{|c|}{ CTA Min/Max AR Ratio } \\
\hline $\begin{array}{l}\text { Y-Index } \\
\mathrm{CP}=0.810\end{array}$ & $\begin{array}{l}0.90(0.81-0.96) \\
{[71 / 79]}\end{array}$ & $\begin{array}{l}0.99(0.92-1.00) \\
{[64 / 66]}\end{array}$ & $0.96(0.78-0.99)$ & $0.96(0.92-0.98)$ \\
\hline $\begin{array}{l}\text { Specificity } \geq 0.70 \\
\mathrm{CP}=0.889\end{array}$ & $\begin{array}{l}0.95(0.88-0.99) \\
{[75 / 79]}\end{array}$ & $\begin{array}{l}0.83(0.72-0.91) \\
{[55 / 66]}\end{array}$ & $0.71(0.59-0.81)$ & $0.98(0.94-0.99)$ \\
\hline \multicolumn{5}{|c|}{ CTA M2 Territory Asymmetry Ratio } \\
\hline $\begin{array}{l}\text { Y-Index } \\
\mathrm{CP}=0.922\end{array}$ & $0.87(0.80-0.95)[69 / 79]$ & $\begin{array}{l}0.97(0.90-1.00) \\
{[65 / 66]}\end{array}$ & $0.93(0.76-0.98)$ & $0.95(0.91-0.97)$ \\
\hline $\begin{array}{l}\text { Specificity } \geq 0.70 \\
\mathrm{CP}=0.941\end{array}$ & $\begin{array}{l}0.91(0.83-0.96) \\
{[72 / 79]}\end{array}$ & $\begin{array}{l}0.83(0.72-0.91) \\
{[55 / 66]}\end{array}$ & $0.70(0.58-0.80)$ & $0.96(0.92-0.99)$ \\
\hline \multicolumn{5}{|c|}{ ICA + M1-Occlusion $(n=72)$ vs. Controls $(n=66)$} \\
\hline \multicolumn{5}{|c|}{ CTA Hemispheric AR } \\
\hline $\begin{array}{l}\text { Y-Index } \\
\mathrm{CP}=0.926\end{array}$ & $\begin{array}{l}0.92(0.83-0.97) \\
{[66 / 72]}\end{array}$ & $\begin{array}{l}0.97(0.90-1.00) \\
{[64 / 66]}\end{array}$ & $0.93(0.77-0.98)$ & $0.96(0.93-0.98)$ \\
\hline $\begin{array}{l}\text { Specificity } \geq 0.70 \\
\mathrm{CP}=0.955\end{array}$ & $\begin{array}{l}0.99(0.93-1.000) \\
{[71 / 72]}\end{array}$ & $\begin{array}{l}0.77(0.65-0.87) \\
{[51 / 66]}\end{array}$ & $0.65(0.54-0.74)$ & $0.99(0.95-1.00)$ \\
\hline \multicolumn{5}{|c|}{ CTA Min/Max AR Ratio } \\
\hline $\begin{array}{l}\text { Y-Index } \\
\mathrm{CP}=0.810\end{array}$ & $\begin{array}{l}0.93(0.85-0.97) \\
{[67 / 72]}\end{array}$ & $\begin{array}{l}0.99(0.92-1.00) \\
{[65 / 66]}\end{array}$ & $0.96(0.79-1.00)$ & $0.97(0.93-0.99)$ \\
\hline $\begin{array}{l}\text { Specificity } \geq 0.70 \\
\mathrm{CP}=0.955\end{array}$ & $\begin{array}{l}0.97(0.90-1.00) \\
{[70 / 72]}\end{array}$ & $\begin{array}{l}0.88(0.78-0.95) \\
{[58 / 66]}\end{array}$ & $0.78(0.64-0.87)$ & $0.99(0.95-1.00)$ \\
\hline \multicolumn{5}{|c|}{ CTA M2 Territory AR } \\
\hline $\begin{array}{l}\text { Y-Index } \\
\mathrm{CP}=0.922\end{array}$ & $\begin{array}{l}0.90(0.83-0.97) \\
{[65 / 72]}\end{array}$ & $\begin{array}{l}0.97(0.90-1.00) \\
{[64 / 66]}\end{array}$ & $0.93(0.77-0.98)$ & $0.96(0.93-0.98)$ \\
\hline $\begin{array}{l}\text { Specificity } \geq 0.70 \\
\mathrm{CP}=0.955\end{array}$ & $\begin{array}{l}0.93(0.85-0.98) \\
{[67 / 72]}\end{array}$ & $\begin{array}{l}0.83(0.72-0.91) \\
{[55 / 66]}\end{array}$ & $0.71(0.58-0.81)$ & $0.97(0.92-0.99)$ \\
\hline
\end{tabular}

Notably, complex processing of 4D CTP data is necessary to produce reliable results and correct for different hemodynamics, which is not applicable for the described technique and CTA imaging in general. Nevertheless, attenuation changes on CTASI have frequently presented high sensitivity for ischemia and correlation with cerebral blood flow CTP maps [12, 21, 22]. This including our data indicate that CTA using bolus trigger seem to produce robust attenuation phases that are highly sensitive for tissue ischemia similar to CTP. Thereby, automated ischemia detection on CTA, as we examined, could complement other software solutions focusing on LVO localization in order to produce higher and more robust detection rates or even pose as surrogate for CTP.

For PSCs, where only CTA might be available as advanced imaging modality, these encouraging results indicate a benefit, as software-assisted diagnosis can elevate diagnostic confidence and support on call radiologists or neurologists without extensive experience in stroke imag- ing. This is an important safety aspect for CTA assessment as variability with only fair interreader agreement in LVO detection is known [10]. In a retrospective study the rate of initially missed LVO stroke was $20 \%$, being highly associated with reader experience [8]. Especially distal occlusion seems to challenge interpreting doctors with reported sensitivities as low as 33\% [9].

Relating these numbers with the proportion of LVO stroke patients at stroke centers of around 24-38\% [1, 2,23 implicates a relevant number of patients who are under risk of erroneous treatment decision. Especially in times with proven treatment effects of EVT up to $24 \mathrm{~h}$ and indicated effectiveness even outside the RCT criteria, the identification of treatable LVO is paramount [4, 5, 24, 25]. The range of sensitivities of our examined parameters from 0.87 to 0.99 for proximal and from 0.57 to 0.86 for distal occlusion therefore indicate a promising approach to augment visual analysis and secure correct patient selection. 
Table 3 (Continued)

\begin{tabular}{|c|c|c|c|c|}
\hline Method/cut point & $\begin{array}{l}\text { Sensitivity }(95 \% \text { CI) } \\
\text { [raw \#] }\end{array}$ & $\begin{array}{l}\text { Specificity }(95 \% \text { CI) } \\
\text { [raw \#] }\end{array}$ & $\mathrm{PPV}^{*}$ & NPV* \\
\hline \multicolumn{5}{|c|}{ M2 Occlusions $(n=7)$ vs. Controls $(n=66)$} \\
\hline \multicolumn{5}{|c|}{ CTA Hemispheric AR } \\
\hline $\begin{array}{l}\text { Y-Index } \\
\mathrm{CP}=0.935\end{array}$ & $\begin{array}{l}0.57(0.18-0.90) \\
{[4 / 7]}\end{array}$ & $\begin{array}{l}0.94(0.85-0.98) \\
{[62 / 66]}\end{array}$ & $0.28(0.11-0.55)$ & $0.98(0.96-0.99)$ \\
\hline $\begin{array}{l}\text { Specificity } \geq 0.70 \\
\mathrm{CP}=0.955\end{array}$ & $\begin{array}{l}0.71(0.20-0.96) \\
{[5 / 7]}\end{array}$ & $\begin{array}{l}0.77(0.65-0.87) \\
{[51 / 66]}\end{array}$ & $0.12(0.06-0.20)$ & $0.99(0.95-1.00)$ \\
\hline \multicolumn{5}{|c|}{ CTA Min/Max AR Ratio } \\
\hline $\begin{array}{l}\text { Y-Index } \\
\mathrm{CP}=0.785\end{array}$ & $\begin{array}{l}0.57(0.18-0.90) \\
{[4 / 7]}\end{array}$ & $\begin{array}{l}1.0(0.95-1.00) \\
{[66 / 66]}\end{array}$ & $1.00(1.00-1.00)$ & $0.98(0.96-0.99)$ \\
\hline $\begin{array}{l}\text { Specificity } \geq 0.70 \\
\mathrm{CP}=0.889\end{array}$ & $\begin{array}{l}0.71(0.29-0.96) \\
{[5 / 7]}\end{array}$ & $\begin{array}{l}0.83(0.72-0.91) \\
{[51 / 66]}\end{array}$ & $0.15(0.08-0.27)$ & $0.99(0.96-1.00)$ \\
\hline \multicolumn{5}{|c|}{ CTA M2 Territory AR } \\
\hline $\begin{array}{l}\text { Y-Index } \\
\mathrm{CP}=0.941\end{array}$ & $\begin{array}{l}0.71(0.29-0.96) \\
{[5 / 7]}\end{array}$ & $\begin{array}{l}0.83(0.72-0.91) \\
{[55 / 66]}\end{array}$ & $0.15(0.08-0.27)$ & $0.99(0.96-1.00)$ \\
\hline $\begin{array}{l}\text { Specificity } \geq 0.70 \\
\text { (same as above) }\end{array}$ & $\begin{array}{l}0.71(0.29-0.96) \\
{[5 / 7]}\end{array}$ & $\begin{array}{l}0.83(0.72-0.91) \\
{[55 / 66]}\end{array}$ & $0.15(0.08-0.27)$ & $0.99(0.96-1.00)$ \\
\hline \multicolumn{5}{|c|}{ CTA M5 ASPECTS Region AR } \\
\hline $\begin{array}{l}\text { Y-Index } \\
\mathrm{CP}=0.919\end{array}$ & $\begin{array}{l}0.86(0.42-1.00) \\
{[6 / 7]}\end{array}$ & $\begin{array}{l}0.92(0.83-0.98) \\
{[61 / 66]}\end{array}$ & $0.32(0.16-0.54)$ & $0.99(0.96-1.00)$ \\
\hline $\begin{array}{l}\text { Specificity } \geq 0.70 \\
\text { (same as above) }\end{array}$ & $\begin{array}{l}0.86(0.42-1.00) \\
{[6 / 7]}\end{array}$ & $\begin{array}{l}0.92(0.83-0.98) \\
{[61 / 66]}\end{array}$ & $0.32(0.16-0.54)$ & $0.99(0.96-1.00)$ \\
\hline
\end{tabular}

Performance metrics for the indicated parameters are displayed as value $(95 \%-\mathrm{CI})$ [raw numbers]. CP were determined by the Y-Index and sensitivity threshold of $\geq 0.70$. To calculate PPV and NPV a rate of overall LVO stroke patients of $30 \%$ and specifically M 2 occlusion patients of $4 \%$ was assumed

$L V O$ indicates large-vessel occlusion, $C I$ confidence interval, $P P V$ positive predictive value, $N P V$ negative predictive value, $Y$-Index Youden Index, $C P$ cut point, Spec specificity, CTA CT angiography, $A R$ asymmetry ratio, ICA internal carotid artery, $M 1 \mathrm{M} 1$ segment of the middle cerebral artery, $M 2 \mathrm{M} 2$ segment of the middle cerebral artery, ASPECTS Alberta Stroke Program Early CT Score

Notably, these results might change in studies on larger patient cohorts and in the real-life setting.

Recognizing the large number of transferred stroke patients in recent trials [26], the decision to transfer relies heavily on imaging interpretation at PSCs. Here the interpretation of CT and especially CTA examinations represent a relevant time span and cause of delay in the management of patients $[7,27]$. While the additional use of CTP would significantly improve sensitivity over CTA and noncontrast CT alone even for experienced neuroradiologists [9], availability is not universal, especially among PSCs and can also cause further delay [28, 29]. Our reported sensitivity/specificity metrics would result in an overall PPV of $0.65-0.96$ and NPV of 0.96-0.98. This would result in effectively ruling out LVO in suspected stroke while supporting further assessment or transfer in positive cases.

The high accuracy of the described technique encourages further studies in primary and secondary stroke centers in a prospective setting. Processing times of around $5 \mathrm{~min}$ using the nonoptimized software prototype also present a suitable timeframe; however this parameter was not systematically examined.

The results of our study have to be regarded in the light of the limitations. First, we only provide a limited dataset.
As we present an experimental approach, the stroke negative group was highly selected without signs of ischemia on admission CTP and follow-up to ensure unbiased results. Also, patients with prior stroke were excluded in the study analysis. To further translate these methods to the clinical setting, our findings, therefore, need replication in larger prospective studies on consecutive patients including measurements of time to diagnosis and time to treatment as well as analysis of diagnostic accuracy. Notably, we strongly assume that patients with lacunar stroke without LVO, who were excluded in our study, would not greatly change the results as even CTP presents only reduced sensitivity in the acute phase [30].

Second, we only relied on a single vendor for the study using a modern CTA protocol. These protocols have been shown to overestimate the ischemic core, yet they provide a very sensitive approach to ischemia detection [21]. Therefore, translation between different platforms and protocols needs further assessment.

Third, our results are limited by the software design to perform regional attenuation measurements according to the implemented ASPECTS template. A template-free, voxelwise approach might provide a more genuine assessment of 


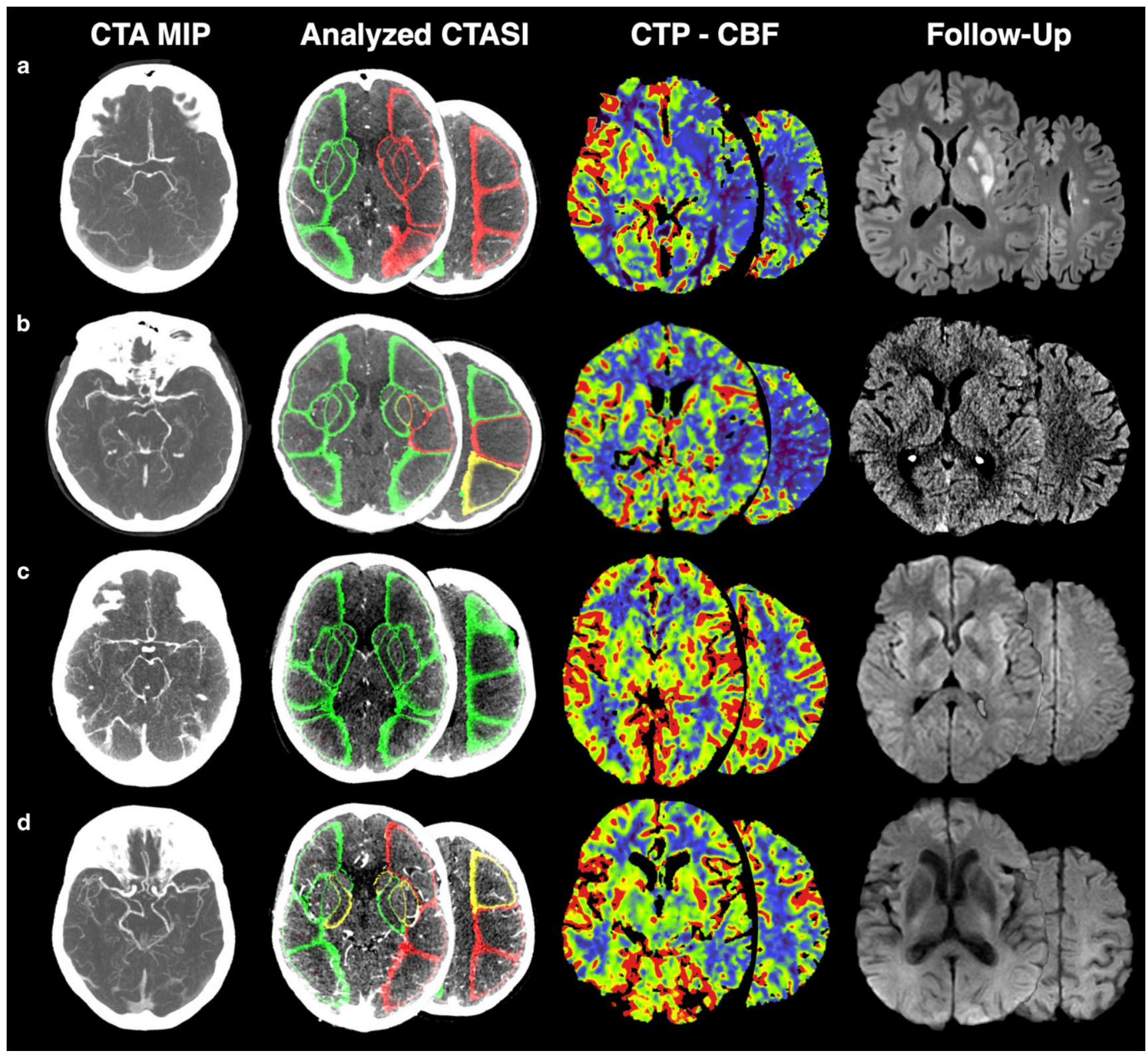

Fig. 2 Examples of LVO classification. a Patient with left sided M1 occlusion. Analyzed CTASI present attenuation decrease in the affected hemisphere in the same regions as seen on CTP. This patient was correctly classified by all parameters. Follow-up MRI displays basal ganglia infarction after successful thrombectomy. b Patient with left sided occlusion of the proximal M2 segment. Analyzed CTASI present attenuation changes in few regions of the M2 territory. This patient was wrongly classified by CTA hemispheric AR as stroke negative but correctly classified by the other parameters CTA Min/Max AR Ratio, CTA M2 Territory Asymmetry Ratio, CTA M5 ASPECTS Region AR as LVO stroke. Follow-up CT displays slight blur of the insular ribbon after successful thrombectomy. $\mathbf{c}$ Patient who presented with right hemihypesthesia. Analyzed CTASI present equal attenuation on both hemispheres. No hypoperfusion is seen on CTP. This patient was correctly classified as LVO stroke negative by all parameters. Follow-up MRI displays no infarction. d Patient who presented with new dysarthria and headache. No occlusion on CTA or hypoperfusion on CTP is detectably. Analyzed CTASI present attenuation changes in few regions of left hemisphere. This patient was wrongly classified by all parameters as LVO stroke positive. Follow-up CT displays no infarction (LVO large-vessel occlusion, CTA CT angiography, $M I P$ maximum intensity projection, CTASI CTA source images, CTP CT perfusion, $C B F$ cerebral blood flow, MI M1 segment of the middle cerebral artery, $M 2 \mathrm{M} 2$ segment of the middle cerebral artery, $A R$ asymmetry ratio) 
ischemic attenuation changes on CTASI but was not available to us for this study.

In conclusion, attenuation measurements on CTASI identify proximal LVO stroke of the anterior circulation with high sensitivity and specificity and can therefore aid in accurate and timely patient selection for thrombectomy.

Author Contribution Paul Reidler: conceptualization, methodology, formal analysis, investigation, writing-original draft, supervision; Lena Stueckelschweiger: formal analysis, investigation, writing-original draft; Daniel Puhr-Westerheide: formal analysis, investigation, writing - original draft; Katharina Feil: conceptualization, writing-review \& editing; Lars Kellert: conceptualization, writing-review \& editing; Konstantinos Dimitriadis: conceptualization, writing-review \& editing; Steffen Tiedt: conceptualization, writing-original draft; Moriz Herzberg: conceptualization, methodology, writing - original draft; Jan Rémi: conceptualization, methodology, writing-original draft; Thomas Liebig: conceptualization, methodology, writing — original draft; Matthias P. Fabritius and Wolfgang G. Kunz: conceptualization, formal analysis, investigation, writing-original draft project administration.

Funding Open Access funding provided by Projekt DEAL.

\section{Compliance with ethical guidelines}

Conflict of interest P. Reidler, L. Stueckelschweiger, D. Puhr-Westerheide, K. Feil, L. Kellert, K. Dimitriadis, S. Tiedt, M. Herzberg, J. Rémi, T. Liebig, M.P. Fabritius and W.G. Kunz declare no relationships with any companies, whose products or services may be related to the subject matter of the article.

Ethical standards Institutional review board approval was obtained. Written informed consent was waived by the institutional review board.

Open Access This article is licensed under a Creative Commons Attribution 4.0 International License, which permits use, sharing, adaptation, distribution and reproduction in any medium or format, as long as you give appropriate credit to the original author(s) and the source, provide a link to the Creative Commons licence, and indicate if changes were made. The images or other third party material in this article are included in the article's Creative Commons licence, unless indicated otherwise in a credit line to the material. If material is not included in the article's Creative Commons licence and your intended use is not permitted by statutory regulation or exceeds the permitted use, you will need to obtain permission directly from the copyright holder. To view a copy of this licence, visit http://creativecommons.org/licenses/by/4. $0 /$.

\section{References}

1. Malhotra K, Gornbein J, Saver JL. Ischemic strokes Due to largevessel occlusions contribute disproportionately to stroke-related dependence and death: a review. Front Neurol. 2017;8:651.

2. Dozois A, Hampton L, Kingston CW, Lambert G, Porcelli TJ, Sorenson D, Templin M, VonCannon S, Asimos AW. PLUMBER Study (Prevalence of Large Vessel Occlusion Strokes in Mecklenburg County Emergency Response). Stroke. 2017;48:3397-9.

3. Goyal M, Menon BK, van Zwam WH, Dippel DW, Mitchell PJ, Demchuk AM, Dávalos A, Majoie CB, van der Lugt A, de Miquel MA, Donnan GA, Roos YB, Bonafe A, Jahan R, Diener HC, van den Berg LA, Levy EI, Berkhemer OA, Pereira VM, Rempel J, Millán M, Davis SM, Roy D, Thornton J, Román LS, Ribó M, Beumer
D, Stouch B, Brown S, Campbell BC, van Oostenbrugge RJ, Saver JL, Hill MD, Jovin TG; HERMES collaborators. Endovascular thrombectomy after large-vessel ischaemic stroke: a meta-analysis of individual patient data from five randomised trials. Lancet. 2016;387:1723-31.

4. Nogueira RG, Jadhav AP, Haussen DC, Bonafe A, Budzik RF, Bhuva P, Yavagal DR, Ribo M, Cognard C, Hanel RA, Sila CA, Hassan AE, Millan M, Levy EI, Mitchell P, Chen M, English JD, Shah QA, Silver FL, Pereira VM, Mehta BP, Baxter BW, Abraham MG, Cardona P, Veznedaroglu E, Hellinger FR, Feng L, Kirmani JF, Lopes DK, Jankowitz BT, Frankel MR, Costalat V, Vora NA, Yoo AJ, Malik AM, Furlan AJ, Rubiera M, Aghaebrahim A, Olivot JM, Tekle WG, Shields R, Graves T, Lewis RJ, Smith WS, Liebeskind DS, Saver JL, Jovin TG; DAWN Trial Investigators. Thrombectomy 6 to 24 Hours after Stroke with a Mismatch between Deficit and Infarct. N Engl J Med. 2018;378:11-21.

5. Albers GW, Marks MP, Kemp S, Christensen S, Tsai JP, OrtegaGutierrez S, McTaggart RA, Torbey MT, Kim-Tenser M, LeslieMazwi T, Sarraj A, Kasner SE, Ansari SA, Yeatts SD, Hamilton S, Mlynash M, Heit JJ, Zaharchuk G, Kim S, Carrozzella J, Palesch YY, Demchuk AM, Bammer R, Lavori PW, Broderick JP, Lansberg MG; DEFUSE 3 Investigators. Thrombectomy for Stroke at 6 to 16 Hours with Selection by Perfusion Imaging. N Engl J Med. 2018;378:708-18.

6. Wintermark M, Luby M, Bornstein NM, Demchuk A, Fiehler J, Kudo K, Lees KR, Liebeskind DS, Michel P, Nogueira RG, Parsons MW, Sasaki M, Wardlaw JM, Wu O, Zhang W, Zhu G, Warach SJ. International survey of acute stroke imaging used to make revascularization treatment decisions. Int J Stroke. 2015;10:759-62.

7. Almekhlafi MA, Kunz WG, Menon BK, McTaggart RA, Jayaraman MV, Baxter BW, Heck D, Frei D, Derdeyn CP, Takagi T, Aamodt AH, Fragata IMR, Hill MD, Demchuk AM, Goyal M. Imaging of Patients with Suspected Large-Vessel Occlusion at Primary Stroke Centers: Available Modalities and a Suggested Approach. AJNR Am J Neuroradiol. 2019;40:396-400.

8. Fasen BACM, Heijboer RJJ, Hulsmans FH, Kwee RM. CT Angiography in Evaluating Large-Vessel Occlusion in Acute Anterior Circulation Ischemic Stroke: Factors Associated with Diagnostic Error in Clinical Practice. AJNR Am J Neuroradiol. 2020;41:607-11.

9. Becks MJ, Manniesing R, Vister J, Pegge SAH, Steens SCA, van Dijk EJ, Prokop M, Meijer FJA. Brain CT perfusion improves intracranial vessel occlusion detection on CT angiography. J Neuroradiol. 2019;46:124-9.

10. Yu AY, Zerna C, Assis Z, Holodinsky JK, Randhawa PA, Najm M, Goyal M, Menon BK, Demchuk AM, Coutts SB, Hill MD. Multiphase CT angiography increases detection of anterior circulation intracranial occlusion. Neurology. 2016;87:609-16.

11. Powers WJ, Rabinstein AA, Ackerson T, Adeoye OM, Bambakidis NC, Becker K, Biller J, Brown M, Demaerschalk BM, Hoh B, Jauch EC, Kidwell CS, Leslie-Mazwi TM, Ovbiagele B, Scott PA, Sheth KN, Southerland AM, Summers DV, Tirschwell DL. Guidelines for the Early Management of Patients With Acute Ischemic Stroke: 2019 Update to the 2018 Guidelines for the Early Management of Acute Ischemic Stroke: A Guideline for Healthcare Professionals From the American Heart Association/American Stroke Association. Stroke. 2019;50:e344-418. Erratum in: Stroke. 2019;50:e4401.

12. Sharma M, Fox AJ, Symons S, Jairath A, Aviv RI. CT angiographic source images: flow- or volume-weighted? AJNR Am J Neuroradiol. 2011;32:359-64.

13. Reidler P, Thierfelder KM, Rotkopf LT, Fabritius MP, Puhr-Westerheide D, Dorn F, Forkert ND, Kemmling A, Kunz WG. Attenuation Changes in ASPECTS Regions: A Surrogate for CT Perfusion-based Ischemic Core in Acute Ischemic Stroke. Radiology. 2019;291:451-8. 
14. Rai AT, Seldon AE, Boo S, Link PS, Domico JR, Tarabishy AR, Lucke-Wold N, Carpenter JS. A population-based incidence of acute large vessel occlusions and thrombectomy eligible patients indicates significant potential for growth of endovascular stroke therapy in the USA. J Neurointerv Surg. 2017;9:722-6.

15. Rai AT, Domico JR, Buseman C, Tarabishy AR, Fulks D, LuckeWold N, Boo S, Carpenter JS. A population-based incidence of M2 strokes indicates potential expansion of large vessel occlusions amenable to endovascular therapy. J Neurointerv Surg. 2018;10:510-5.

16. Amukotuwa SA, Straka M, Smith H, Chandra RV, Dehkharghani S, Fischbein NJ, Bammer R. Automated Detection of Intracranial Large Vessel Occlusions on Computed Tomography Angiography: A Single Center Experience. Stroke. 2019;50:2790-8.

17. Barreira CM, Bouslama M, Haussen DC, Grossberg JA, Baxter B, Devlin T, Frankel M, Nogueira RG. Abstract WP61: Automated Large Artery Occlusion Detection IN Stroke Imaging-ALADIN Study. International Stroke Conference 2018. https://doi.org/10. 1161/str.49.suppl_1.WP61

18. Chatterjee A, Somayaji NR, Kabakis IM. Abstract WMP16: Artificial intelligence detection of cerebrovascular large vessel occlusion-nine month, 650 patient evaluation of the diagnostic accuracy and performance of the viz.ai LVO algorithm. International Stroke Conference 2019, https://doi.org/10.1161/str.50.suppl_1.WMP16.

19. Tolhuisen ML, Ponomareva E, Koopman MS, Jansen IG, Boers AM, Majoie CB, Marquering HA. Abstract WP70: Artificial intelligence based detection of large vessel occlusion on non-contrast computed tomography in stroke. International Stroke Conference 2019, https://doi.org/10.1161/str.50.suppl_1.WP70.

20. Murray NM, Unberath M, Hager GD, Hui FK. Artificial intelligence to diagnose ischemic stroke and identify large vessel occlusions: a systematic review. J Neurointerv Surg. 2020;12:156-64.

21. Pulli B, Schaefer PW, Hakimelahi R, Chaudhry ZA, Lev MH, Hirsch JA, González RG, Yoo AJ. Acute ischemic stroke: infarct core estimation on CT angiography source images depends on CT angiography protocol. Radiology. 2012;262:593-604.

22. Mukherjee A, Muthusami P, Mohimen A, Srinivasan K, Babunath B, Sylaja PN, Kesavadas C. Noncontrast computed tomography versus computed tomography angiography source images for predicting final infarct size in anterior circulation acute ischemic stroke: a prospective cohort study. J Stroke Cerebrovasc Dis. 2017;26:339-46.

23. Desai SM, Starr M, Molyneaux BJ, Rocha M, Jovin TG, Jadhav AP. Acute Ischemic Stroke with Vessel Occlusion-Prevalence and Thrombectomy Eligibility at a Comprehensive Stroke Center. J Stroke Cerebrovasc Dis. 2019;28:104315.

24. Desai SM, Rocha M, Molyneaux BJ, Starr M, Kenmuir CL, Gross BA, Jankowitz BT, Jovin TG, Jadhav AP. Thrombectomy 6-24 hours after stroke in trial ineligible patients. J Neurointerv Surg. 2018;10:1033-7.

25. Kaesmacher J, Chaloulos-Iakovidis P, Panos L, Mordasini P, Michel P, Hajdu SD, Ribo M, Requena M, Maegerlein C, Friedrich B, Costalat V, Benali A, Pierot L, Gawlitza M, Schaafsma J, Mendes Pereira V, Gralla J, Fischer U. Mechanical Thrombectomy in Ischemic Stroke Patients With Alberta Stroke Program Early Computed Tomography Score 0-5. Stroke. 2019;50:880-8.

26. Sarraj A, Mlynash M, Savitz SI, Heit JJ, Lansberg MG, Marks MP, Albers GW. Outcomes of Thrombectomy in Transferred Patients With Ischemic Stroke in the Late Window: A Subanalysis From the DEFUSE 3 Trial. JAMA Neurol. 2019;76:682-9.

27. Al Kasab S, Almallouhi E, Harvey J, Turner N, Debenham E, Caudill J, Holmstedt CA, Switzer JA. Door in door out and transportation times in 2 telestroke networks. Neurol Clin Pract. 2019;9:41-7.

28. Meretoja A, Keshtkaran M, Tatlisumak T, Donnan GA, Churilov L. Endovascular therapy for ischemic stroke: Save a minute-save a week. Neurology. 2017;88:2123-7.

29. Menon BK, Sajobi TT, Zhang Y, Rempel JL, Shuaib A, Thornton J, Williams D, Roy D, Poppe AY, Jovin TG, Sapkota B, Baxter BW, Krings T, Silver FL, Frei DF, Fanale C, Tampieri D, Teitelbaum J, Lum C, Dowlatshahi D, Eesa M, Lowerison MW, Kamal NR, Demchuk AM, Hill MD, Goyal M. Analysis of Workflow and Time to Treatment on Thrombectomy Outcome in the Endovascular Treatment for Small Core and Proximal Occlusion Ischemic Stroke (ESCAPE) Randomized, Controlled Trial. Circulation. 2016;133:2279-86.

30. Benson JC, Payabvash S, Mortazavi S, Zhang L, Salazar P, Hoffman B, Oswood M, McKinney AM. CT Perfusion in Acute Lacunar Stroke: Detection Capabilities Based on Infarct Location. AJNR Am J Neuroradiol. 2016;37:2239-44. 